\title{
ZIARAH DAN RELASI SUNNI-SYIAH: \\ Akar Serangan Mematikan Terhadap Peziarah Di Pakistan
}

\section{Muhammad Tarobin}

Balitbang, Kemenag RI

Tarobin799PF@gmail.com

\section{Abstract}

One of the areas that had conflict and the deadliest religious conflicts and violence in Islam world is in Pakistan, a Nation that has strong and profound Islamic tradition. Muslims in Pakistan are around 180 millions population, and 15 percent among them are followers of Shia madzhab. It has been three decades since Pakistan was declared in 17 August 1947, Sunni and Shia community lived in Harmony. However, ahead of Islamic revolution in Iran in 1979, Sunni-Shia's relation heated up. In the last two decades, Pakistan region has become the deadliest region, especially for Pakistan Shia Pilgrims. This paper tries to see the root of the problems. Based on study toward literary materials, there are three factors causing Sunni-Shia conflict in Pakistan, which are : by the appointment of General Muhammad Zia-ul-Haq in the authority (1977), The Iranian Islamic Revolution in 1979, and the politics of nerve war in border Kashmir and Afganistan. Nevertheles, conflicts and the deadly violence are more complex due to power competition in the country and intervention from United States, Saudi Arabia, and Iran.

Keywords: Wali, Tawassul bi al-Dhāt, Salafi-Wahabi, Imāmiyah. 


\section{Abstrak}

Salah satu wilayah yang mengalami konflik dan kekerasan keagamaan paling mematikan di dunia Islam adalah Pakistan, negara yang memiliki tradisi keIslaman cukup kuat dan mengakar. Umat Muslim di Pakistan berjumlah sekitar 180 juta, dan 15 persen diantaranya merupakan penganut mazhab Syiah. Telah tiga dasawarsa sejak Pakistan didirikan pada 17 Agustus 1947, komunitas Sunni dan Syiah hidup dalam suasana harmonis. Namun menjelang revolusi Islam di Iran pada 1979, hubungan Sunni-Syiah memanas. Dua dasawarsa terakhir wilayah Pakistan menjadi wilayah paling mematikan, khususnya bagi peziarahpeziarah Syiah Pakistan. Tulisan ini hendak melihat akar permasalahan tersebut. Berdasarkan telaah terhadap bahanbahan tertulis, ada tiga faktor yang menyulut konflik SunniSyiah di Pakistan, yakni: naiknya Jenderal Muhammad Zia-ulHaq dalam tampuk kekuasaan (tahun 1977), Revolusi Islam Iran tahun 1979, dan politik perang syaraf di perbatasan Kashmir dan Afghanistan. Namun, konflik dan kekerasan mematikan tersebut semakin kompleks akibat persaingan kekuasaan di dalam negeri, dan campur tangan Amerika Serikat, Saudi Arabia, dan Iran.

Kata Kunci: Wali, Tawassul bi al-Dhāt, Salafi-Wahabi, Imāmiyah. 


\section{A. PENDAHULUAN}

Tradisi ziarah terkait langsung dengan persepsi tentang sejauh mana hubungan antara manusia dengan Allah dan

L segala sesuatu tentang Allah. Persepsi ini lantas mengaktual, melahirkan suatu konsep yang dikenal sebagai "wali." Para nabi adalah wali-wali tertinggi yang memiliki "pengetahuan terbaik" tentang Allah. Selain para nabi, kaum Syiah juga mempercayai bahwa para Imam mereka mencapai derajat spiritual terbaik untuk mendekat sedekat-dekatnya dengan Allah. Persepsi ini muncul akibat adanya keperluan manusia untuk mencapai maksud hakiki kepada Tuhan Yang Maha Mutlak dan keperluan akan adanya "wahyu" yang selalu aktual. Sebaliknya, kaum Hanbali "ekstrem" seperti kaum Salafi-Wahabi di Saudi Arabia ${ }^{1}$ menolak kemungkinan bahwa seorang "perantara" dapat mendekatkan manusia dengan Allah ataupun turut menyalurkan rahmat-Nya.

Konsep wali tersebut melahirkan konsep-konsep turunan seperti berkah (tabarruk), wasillah (tawassul), dan tradisi ziarah. Pembahasan tentang ziarah ini penting ketika dihubungkan dengan konteks praktik kerukunan antara Sunni-Syiah. Dialog atau bahkan "persatuan" antara Sunni-Syiah akan sulit terwujud ketika dalam dua dasawarsa terakhir, serangan-serangan fisik mematikan terhadap komunitas Syiah sering terjadi. Seranganserangan tersebut, seperti akan disebutkan di bawah, sebagian besar justru menyasar masyarakat sipil peziarah Syiah di Pakistan yang berbatasan langsung dengan Iran. Demikian juga di beberapa tempat di Timur Tengah.

Tulisan ini sebetulnya ingin mengambil pelajaran dari suatu negara (Pakistan) yang memiliki tradisi keIslaman cukup kuat namun dalam dua dasawarsa terakhir dilanda konflik dan kekerasan mematikan. Penulis akan melihat aspek ziarah melalui tiga perspektif, yakni: perbedaan konseptual dalam tradisi Sunni ortodoks, Salafi-Wahabi, dan Syiah. Kedua, menelaah praktik ziarah

1 Richard C. Martin mencontohkan bahwa toleransi terhadap para peziarah tidak terjadi di wilayah-wilayah yang didominasi oleh Hanbali, untuk kasus Saudi Arabia misalnya terjadi sejak Wahabi dan Salafi puritan menguasai Jazirah Arabia pada awal abad XVIII. Lihat, Richard C. Martin, “Ziyara”, dalam Richard C. Martin, (ed.), Encyclopedia of Islam, h. 533. 
dalam pendekatan antropologis. Ketiga, melihat peziarah Syiah di Pakistan sebagai korban konflik kepentingan berbagai pihak.

\section{B. ZIARAH: KONSEP DAN KONTEKS DALAM TRADISI SUNNI}

Istilah Ziyārah (زيارة) berasal dari akar kata kerja lampau zāra (زار), berasal dari kata za-wa-ra (زور). Dalam bahasa Inggris kata ini berarti "to visit, call, pay a visit."' Sedangkan dalam bahasa Indonesia berarti: "mengunjungi, hubungan, dan berkunjung." Pelaku ziarah disebut zā'ir/zā'irūn, zā'irah/zāirāt atau zuwwar/zuwwārāt yang berarti "peziarah-pengunjung, penghubung atau tamu."

Kathryn Kueny ${ }^{4}$ membagi ziarah menjadi dua jenis: pertama ziarah yang diperintahkan dan sudah ditentukan waktunya yakni pada bulan terakhir dalam kalender Hijriyah. Ziarah ini menjadi rukun Islam kelima yakni ibadah haji. Ziarah lainnya ialah ziarah yang "dianjurkan", yakni mengunjungi makam tokoh-tokoh suci atau dianggap suci selain Nabi Muhammad Saw.

Praktik ziarah pada awal Islam pernah dilarang oleh Rasulullah Saw, namun kemudian dianjurkan oleh Rasulullah Saw. hal ini sebagaimana terdapat dalam hadis sahih yang diriwayatkan oleh Ibn Buraydah bahwa Rasulullah Saw. bersabda:

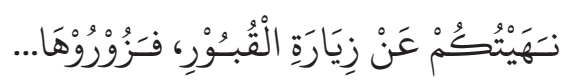

Artinya: "Aku pernah melarang kalian untuk menziarahi kubur, maka (sekarang) ziarahilah kuburan" (HR. Muslim). ${ }^{5}$ Sementara dalam

2 Hans Wehr, A Dictionary of Modern Written Arabic (Beirut-London: Librairie du LibanMacdonald \& Evans LTD, 1974), h. 386.

3 Munir Baalbaki dan Rohi Baalbaki, Kamus al-Maurid, terj. Achmad Sunarto (Surabaya: Halim Jaya, 2006), h. 445.

4 Lihat Kathryn Kueny, "Hajj” dalam Richard C. Martin. (ed.). Encyclopedia of Islam and The Muslim World (USA: Macmillan Reference USA-Thomson Gale, 2003, 529; Bandingkan dengan Mehdi Ebadi, "Shrine Pilgrimage (Ziyārat) in Turco-Iranian Cultural Regions" dalam International Journal of Religious Tourism and Pilgrimage, Vol. 4: Iss. I, Article 7, h. 70.

5 Abū al-Hasan Muslim bin al-Ḥajjāj al-Qushayrī Al-Naysābūrī, Al-Musnad al-Ṣahịḥ alMukhtașar bi Naqi al-'Adl 'an al-'Adl ilá Rasūilllāh Ṣallállähu 'alayhi wa sallam, Tahqiiq: Muhammad Fu'ād 'Abd al-Bāqī (Beirut: Dār Ihyyā' al-Turāth al-'Arabī, t.t.), Juz II, h. 672 (hadis no 977). Hadis tersebut juga diriwayatkan melalui jalur Abī Sa'īd, Anas, Abī Hurayrah, dan Ummi Salamah, sebagaimana diriwayatkan oleh beberapa Imam ahli hadis lain, namun dari kualitas sanad, yang terbaik adalah yang diriwayatkan dalam Sahih Muslim. 
hadis riwayat Abī Dāwud, Rasulullah juga menyebutkan tujuan ziarah yakni untuk mengingat kematian:

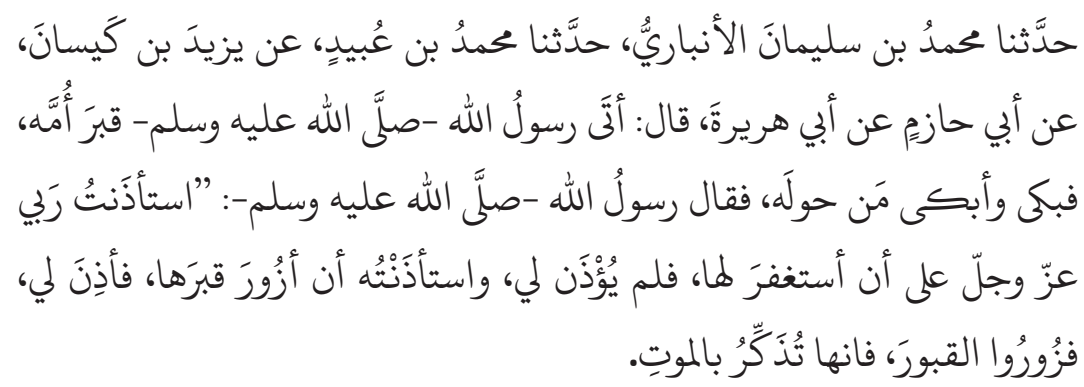

Artinya: "Imam Ab̄i Dāwud berkata, Muhammad bin Sulaymān alAnbārī menceritakan pada kami (ia berkata) Muhammad bin 'Ubayd menceritakan pada kami (ia berkata) dari Yazìd bin Kaysān (ia berkata) dari Abì Hāzim (ia berkata) dari Abī Hurayrah (ia) berkata: Rasulullah Saw. menziarahi kubur ibunya, lalu beliau menangis dan menyebabkan orangyang di sekitarnya ikut menangis. Maka Rasulullah Saw bersabda, "Aku telah meminta izin kepada Tuhanku untuk meminta ampun bagi ibuku, Tuhan tidak mengizinkan aku berbuat demikian. Dan aku meminta izin kepada Tuhanku mengunjungi kubur ibuku, maka Tuhan telah mengizinkannya. Karena itu ziarahilah kubur, karena menziarahi kubur itu mengingatkan kepada kematian." 6

Sedangkan Syekh Muhammad 'Abd al-Ra'ūf al-Munāwī (9521031 H/1545-1622 M) menyebutkan empat kategori dan tujuan ziarah kubur, pertama yakni semata-mata melihat kubur tanpa mengetahui penghuni kubur dan semata-mata untuk mengingat kematian dan kehidupan akhirat. Kedua, untuk mendoakan penghuni kubur, seperti Nabi mendoakan penghuni makam Baqi'. Hal ini dianjurkan bagi ahli kubur Muslim. Ketiga, mencari berkah jika ke makam orang-orang saleh. Keempat, memenuhi hak kepada seseorang sebagai "bakti" bagi ahli kubur. Model ziarah terakhir ini seperti contoh hadis di atas ketika Nabi berziarah ke makam ibunya. ${ }^{7}$ Diantara keempat bentuk ziarah di atas, ziarah dengan

6 Abū Dāwud Sulaymān bin al-Ash'ath bin Isḥāq al-Azdī Al-Sijistānī, Sunan Abī Dāwud, Taḥqīq: Shu'ayb al-Arna'ūṭ, Muḥammad Kāmil Qarah Balilì (Beirut: Dār al-Risālah al-'Ālamiyyah, 2009), Juz V, h. 138.

7 Al-Munāwī, Zayn al-Dīn MuḤammad 'Abd al-Ra'ūf bin Tāj al-Ārifīn al-ḥaddādī, Fayḍ al-Qadīr 
mencari berkah ke makam-makam orang saleh merupakan bentuk ziarah yang paling banyak dikritik terutama ketika dihubungkan dengan pencarian berkah dan tawassul.

Konsep berkah tidak terlepas dari adanya konsep tentang "wali" yang menurut Buehler diperkenalkan oleh al-Hakìm alTirmidhī (w. abad IX/X M) ${ }^{9}$, kemudian dielaborasi lebih lanjut oleh Ibn 'Arabī (w. 1240 M). ${ }^{10}$ Meskipun kata wali jelas memiliki referensi dalam al-Qur'an namun pemaknaanya dalam tradisi Islam dan dalam konteks sosiologis berasal dari peradaban Turki. ${ }^{11}$

Sedangkan istilah berkah secara etimologis berarti bertambah dan berkembang. Sementara tabarruk adalah mencari berkah dari Allah yang terdapat dalam sebuah objek. Prinsip utama dari berkah ialah keyakinan bahwa yang mendatangkan berkah adalah Allah. Hal ini sebagaimana digambarkan oleh hadis sahih dari Bukhari yang mengisahkan tentang air yang keluar dari jari-jari Rasulullah Saw. ${ }^{12}$ Rasulullah juga mengajarkan bagaimana seseorang bertawassul sebagaimana disebutkan dalam sebuah hadis yang diriwayatkan oleh al-Hākim (321-405 H/933-1014/15 M): ${ }^{13}$

Sharḥ al-Jāmi' al-Ṣaghīr (Mesir: Maktabah al-Tijāriyah al-Kubrá, 1356 H (1937/38 M), Juz III, h. 162.

8 Kata "walì" merupakan salah satu dari Nama Allah yang berarti "penolong"; sedangkan kata wilāyah dalam al-Quran berarti pertolongan (al-nușrah dan al-tawliyyah). Kata al-walī dalam al-Quran tidak hanya dinisbahkan kepada Allah, melainkan juga kepada manusia atau setan. Kata al-walī kadang dinisbahkan kepada Allah seperti: Q. S. al-Shūrá (42): 9, al-Nisā (4): 45, al-ḥajj (22): 78; manusia: Yūnus (10): 63, al-Tawbah (9): 71, al-Anfāl (8): 73; Setan: Maryam (19): 45, Al-Nisa (4): 75, 119, dst.. Lihat, Su'ād al-Hakīm, al-Mu'jam al-Ṣüfï: al-Hikmah fỉ hudūd al-kalimah (Beirut: Dandāh Lițtabā'ah wa al-Nashr, 1981), h. 1231-1232.

9 Adalah Abū 'Abdullāh Muhamad bin 'Alī bin Ḥasan (Husayn) bin Bishr, atau digelari alHakīm al-Tirmidhī (berbeda dengan Abū 'İsá Muhammad bin 'Īsá bin Sūrah Al-Tirmidhī (209-279 H/825-892 M), ulama ahli hadis), diperkirakan hidup selama 80-110 tahun, dia lahir pada awal abad ke-3 $\mathrm{H}$ dan meninggal di akhir abad ke-3 $\mathrm{H}$, namun tidak diketahui secara pasti kapan kelahiran dan wafatnya; ada beberapa versi tahun meninggalnya, ada yang menyebut $255 \mathrm{H}(868 / 69 \mathrm{M}), 318 \mathrm{H}$ (930/31 M), 320 H (932 M), 285 H (898/99 M). Lihat, Abū 'Abdullāh Muhammad bin 'Alī bin Hasan al-Ḥakīm al-Tirmidhī, Kitāb Khatm al-Awliyā', Tahqīq: 'Uthmān Ismā'īl Yahyā’ (Beirut: al-Maṭba'ah al-Kāthawlikiyah, t.t), h. 3, 9. Untuk keterangan al-Tirmidhī tentang walī lihat h. 117-127.

10 Arthur F. Buehler, "Saint” dalam Richard C. Martin, (ed.), Encyclopedia of Islam, h. 607-608.

11 Amin Farih, "Paradigma Pemikiran Tawassul dan Tabarruk Sayyid Ahmad Ibn Zaini Dahlan di Tengah Mayoritas Teologi Mazhab Wahabi” dalam Jurnal Theologia, Vol. 27, Nomor 2, Desember 2016, h. 283.

12 Abū 'Abdillāh Muhammad Ibn Ismā'īl al-Bukhārī, Șaḥịh al-Bukhārī, Taḥīiq: Muhammad Zuhayr bin Nāṣir al-Nāṣir (t.k.: Dār Ṭūq al-Najāh, 1422 H/2001/02 M), Juz IV, h. 194 (hadis no. 3579).

13 Abū 'Abdullāh Muḥammad bin 'Abdullāh al-Ḥakim Al-Naysābūrī, Al-Mustadrak 'alá alSahīḥayn li al-Hākim, Taḥīq: Abū 'Abd al-Raḥmān Muqbil (al-Qāhirah: Dār al-Haramayn, 1997), Juz 1, h. 708 (hadis no. 1961); bandingkan dengan h. 715 (hadis no. 1982). 


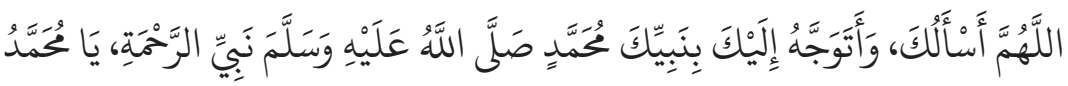

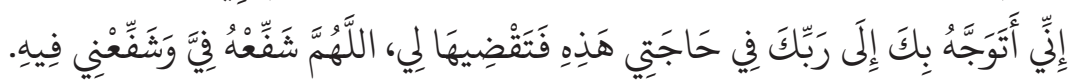
Artinya: "Ya Allah, hamba memohon kepada-Mu dan "menghadap" kepada-Mu dengan Nabi-Mu Muhammad Saw., Nabi pembawa rahmat. Wahai Muhammad (Saw.), saya "menghadap" denganmu kepada Tuhanmu agar Dia menyembuhkan pandanganku. Ya Allah, terimalah syafaatnya untukku dan terimalah syafaatku untuk diriku."

Meskipun kebolehan dan keabsahan tawassul menjadi bahan perdebatan, namun keberadaan doa di atas menjadi bukti bahwa para ulama terdahulu pernah mempraktekkan tawassul. Doa tawassul di atas, terdapat dalam teks Mustadrak al-Hākim yang wafat pada awal abad ke-5 Hijriah/awal abad ke-11 Masehi. Doa di atas, hanya sedikit berbeda dengan doa tawassul yang diamalkan dalam tradisi Syi'ah. Doa tawassul dalam tradisi Syi'ah ini juga secara rutin diamalkan oleh jamaah Ahlul-Bait di Indonesia. Doa tersebut sebagai berikut:

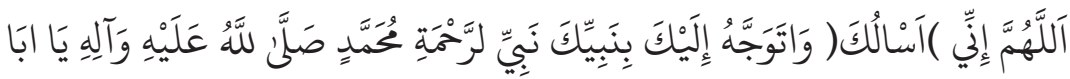

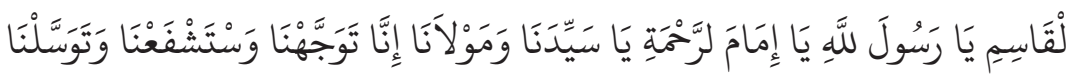

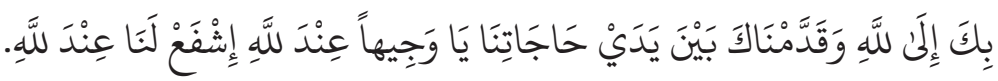
Artinya: "Ya Allah, sesungguhnya aku memohon dan menghadap kepada-Mu dengan (dukungan) Nabi-Mu, Nabi pembawa rahmat, Muhammad, shalawat atasnya dan keluarganya; Wahai Abūl Qāsim, wahai Rasulullah, wahai Imam pembawa rahmat, Wahai junjungan dan pemimpin kami, sesungguhnya kami menghadap, meminta syafaat, dan bertawassul denganmu kepada Allah, serta mengedepankanmu demi terkabulnya hajat-hajat kami, wahai yang terpandang di sisi Allah, karuniakanlah syafaat kepada kami di sisi Allah." ${ }^{4}$

Dengan demikian praktik ziarah di masyarakat, berhubungan dengan pemahaman tentang syafaat, berkah, tawassul, dan tabaruk. Di kalangan Sunni sendiri terdapat dua kecenderungan dalam

14 Ikhlas Budiman (Peny.), Doa Tawassul Doa Kumail Doa Jausyan Kabir (Jakarta: Al-Huda, 2004), 1-2. 
menyikapi perkara-perkara tersebut. Meskipun pada pertumbuhan awal masyarakat Islam, boleh jadi telah terjadi perbedaan, namun perbedaan mulai lebih tajam pada masa Ibnu Taimiyah (661-728 H/1263-1328 M). "Serangan-serangan" kritik terhadap praktik tawassul dan tabarruk kemudian mencapai puncaknya pada masa Muhammad bin Abdul Wahab (1115-1201 H/1703-1787 M).

Dalam hal tawassul, baik kelompok Sunnī pada umumnya maupun Ibn Taimiyah sebetulnya tidak menolak tawassul. Seperti pada umumnya, Ibn Taimiyah mengakui bahwa tawassul bisa diperoleh baik kepada Nabi Muhammad Saw, para sahabat, maupun orang-orang shaleh. Hanya saja, baik Ibn Taimiyah maupun Muhammad bin 'Abdul Wahab, maupun para ulama SalafiWahabi sesudahnya, seperti Nāșir al-Dīn al-Albanī (1914-1999) hanya memperbolehkan tawassul kepada figur yang masih hidup dan mengharamkan tawassul dengan figur yang sudah meninggal (mengharamkan tawassul bi al-dhāt). Sementara kelompok lainnya, misalnya jamaah Nahdlatul Ulama di Indonesia berpendapat bahwa tawassul dapat dilakukan baik kepada figur yang masih hidup maupun yang sudah meninggal (boleh tawassul bi dhāt). ${ }^{15}$

Pemikiran ketiga tokoh di atas, menginspirasi suatu gerakan yang dikenal sebagai salafisme yakni suatu gerakan yang diambil dari terma al-salafal-Șālih, yaitu tiga generasi pertama Muslim yang dipandang sebagai uswah bagi masa depan umat Islam. Salafisme merujuk pada ahl al-hadith sejak masa kekhalifahan Abbasiyah yang memfokuskan studi hadis dengan tujuan untuk membersihkan Islam dari campur tangan non-Muslim. Akar formasi salafisme dirintis oleh Ahmad ibn Hanbal (780-855 M), Ibn Taimiyah, dan dipertegas dalam Wahhabisme oleh Muhammad bin 'Abdul al-Wahhab. Wahhabisme pun kemudian berkembang menjadi salafisme dengan al-Albani sebagai figur yang paling berpengaruh.

Huda $^{16}$ menyebut empat doktrin pokok Salafisme yang

15 M. Ja'far Asshodiq, "Studi Komparasi Tentang Pemahaman Hadis-Hadis Tawassul Munurut Nahdlatul Ulama dan Wahabi” (Surabaya: Tesis Program Studi Imu Hadis Pascasarjana UIN Sunan Ampel, 2018), h. 196.

16 Sokhi Huda, "Global Salafism Perspektif Baru tentang Keunikan Radikalisme Islam" dalam Kontemplasi, Vol. 8, No. 2, Nopember 2011, h. 218. 
terinspirasi Wahhabisme dan sangat berpengaruh dalam hubungan mereka dengan kelompok lain, yakni: pertama, semangat Wahhabisme untuk kembali kepada al-Qur'an dan Hadis, meskipun secara faktual "mengikuti" mazhab Hanbali. Kedua, regulasi hubungan antara mukmin dan non mukmin (outsider). Dalam hal ini, Salafisme memberi perlakuan keras terhadap orang asing dan sekte non Wahhabi. Wahhabi juga mengenal konsep al-Wala' wa al-Bara' (kesetiaan dan penolakan). Wilayah non Wahhabi dikenal sebagai bilād al-mushrikīn. Ketiga, penolakan terhadap mazhab "Syi'ah" sebagai bidah. Penolakan ini didasarkan pada dua alasan, yakni karena Syi’ah mengkultuskan Para Imam, dan Syi'ah menolak tiga diantara Khulafa' al-Rashidūn. Dengan penolakan tersebut Syi'ah dianggap telah menolak para sahabat Nabi dan itu berarti menolak otentisitas Hadis yang merupakan basis Wahhabisme/ Salafisme. Keempat, adanya prakktek "hisba", yakni al-amr bi al-ma'rūf wa al-nahy 'an al-munkar. Praktek ini disebut sebagai puncak jihad oleh Ibn Taimiyah dan dipertahankan oleh SalafismeWahhabisme untuk menegaskan sikap moral secara keras dan meluruskan deviasi seperti merokok, "perlakuan istimewa" terhadap tempat keramat, dan bentuk-bentuk lain yang dipandang syirik. Pada tahun 1920-an praktek Hisba dilembagakan oleh polisi agama (mutawwa/mutawwi'a) di Saudi Arabia.

\section{ZIARAH DAN SYIAH: WARISAN PERSIA KUNO DAN SYIAH IMĀMIYAH DI IRAN}

Pemahaman terhadap konsep Imamah sangat penting untuk menjelaskan mengapa tradisi ziarah di Syi'ah berkembang pesat. $\mathrm{Hal}$ ini tentu bertentangan dengan praktik keagamaan kelompok Salafi-Wahabi di Saudi Arabia. Kepercayaan terhadap Imamah di Iran boleh jadi berakar dalam tradisi Persia kuno. Tradisi Persia kuno, Zarathustra, mengenal suatu pemerintahan yang dipimpin kaum "pendeta" dalam suatu hierarki spiritual di dunia kayangan yang dihuni sejumlah malaikat dan malaikat agung. Kepercayaan ini mengenal suatu lingkaran "cahaya" yang ada sejak dunia ini ada dan akan terus ada sampai akhir zaman. Energi cahaya tersebut 
merupakan "cahaya sakral" untuk menjamin bahwa makhlukmakhluk cahaya tersebut akan memenangkan pertarungan melawan kekuatan perusak. ${ }^{17}$

Masyarakat Turco-Iranian ${ }^{18}$, mempercayai akan adanya siklus manifestasi ${ }^{19}$ wahyu "Tuhan" yang diterima sejak Nabi Adam ${ }^{20}$ sampai 'Alī bin Abū Ṭālib. Siklus manifestasi wahyu tersebut memunculkan konsep tentang "reinkarnasi" dan "transmigrasi" ruhani (the Light Souls). Paham terhadap siklus menifestasi tersebut melahirkan konsep ziyārah dalam tradisi Alawi. Menurut Prager $^{21}$ kaum Alawi di Turki mengenal tiga jenis ziyārah; yakni Khidr-ziyārāt, Nabi ziyārāt, dan Syekh Ziyārāt. Dua jenis ziarah yang pertama merupakan manifestasi terhadap kepercayaan akan reinkarnasi Khidr dan Nabi. Sedangan Syekh ziyārāt selalu dihubungkan dengan transmigrasi ruhani.

Kepercayaan akan wahyu Tuhan yang selalu aktual, dan akan adanya seseorang yang mampu "mengaktualkan" wahyu Tuhan itulah yang melahirkan konsep imamah dalam tradisi Syiah. 'Alī bin Abū Tālib dan 11 orang sesudahnya dalam tradisi Syiah Ithna 'Ashriyyah adalah tokoh yang menurut sumber-sumber Syiah telah ditetapkan oleh Tuhan untuk menjadi imam dan pembimbing bagi umat. Dua belas imam tersebut dianggap memiliki otoritas untuk menafsirkan al-Quran baik secara eksoteris maupun esoteris. ${ }^{22}$

17 Yann Richard, "Iran", dalam Henri Chambert-Loir dan Claude Guillot (ed.), Ziarah dan Wali di Dunia Islam, terj. Jean Couteau, dkk. (Jakarta: Serambi-EFEO-Forum Jakarta Paris), h. 218.

18 Adalah kawasan di Asia Tengah yang pada masa lalu dikenal sebagai Khorasmia, Sogdiana, dan Khurasan, merupakan wilayah di Jalur-Sutra yang menghubungkan antara Timur (Asia) dan Barat (Eropa), serta menjadi pusat pertemuan antara peradaban China, India dan Asia Tengah. Wilayah ini sekarang meliputi: Turki, Iraq, Iran, Pakistan, Afghanistan, Turkmenistan, Azerbaijan, Uzbekistan, Tajikistan, Kyrgystan, Kazakhstan, Xinjian Uyghur (China), dan Tatarstan (Rusia). Untuk studi ini difokuskan di dua negara di kawasan ini, yakni Iran dan Pakistan.

19 Dalam filsafat ishrāq Suhrawardi (w. 1191 M), dimana inti filsafatnya adalah cahaya, disebutkan bahwa cahaya merupakan realitas yang paling nyata. Suhrawardi menyebut bahwa cahaya memiliki sifat "to manifest" yakni menampakkan segala sesuatu. Cahaya dalam pengertian ini tidak difahami dalam pengertian cahaya materil seperti cahaya matahari, atau rembulan, melainkan cahaya dalam makna spiritual. Lihat, Majid Fakhry, Sejarah Filsafat Islam: Sebuah Peta Kronologis, terj. Zaimul Am (Bandung: Mizan, 2002), h. 130-131.

20 Rosihon Anwar, Tafsir Esoterik Al-Qur'an Menurut Al-Thabāthabā̄̄ (Jakarta: Disertasi Program Pascasarjana UIN Syarif Hidayatullah Jakarta, 2003), h. 157.

21 Prager sebagaimana disebut dalam Mehdi Ebadi, "Shrine Pilgrimage (Ziyārat) in TurcoIranian Cultural Regions," dalam International Journal of Religious Tourism and Pilgrimage, Vol. 4: Iss. I, Article 7, h. 71.

22 Anwar, Tafsir Esoterik, h. 156. 
Sementara para ulama lainnya, terutama para ulama sufi, juga sebagian diantaranya berkat anugerah ilmu yang diberikan oleh Allah, melalui latihan-latihan ruhani dianggap memiliki jiwa yang tersucikan serta kemampuan yang memadai untuk memahami maksud kalam Tuhan. Oleh karena itu, mereka juga dianugerahi tanggung jawab oleh Tuhan untuk membimbing umat kepada jalan Tuhan.

Perpaduan antara tradisi Persia kuno, tradisi filsafat, teologi dan sufisme mencapai puncaknya pada pemikiran Shadr al-Dīn alShirāzī (w. 1641 M) atau yang lebih dikenal sebagai Mullā Șadrā. Berdasarkan prinsip bahwa "cahaya" akan selalu ada di sepanjang zaman, Sadra berpendapat bahwa terdapat keharmonisan antara filsafat dan agama. Keharmonisan tersebut menurutnya menunjukkan kebenaran tunggal yang dibawa oleh Nabi Adam As.. Kebenaran tersebut menurutnya, kemudian diturunkan kepada Ibrahim As., para filosof Yunani, lalu para sufi, dan akhirnya para filosof pada umumnya. Para filosof Yunani, menurut dia, menerima "cahaya hikmah" dari "mercusuar kenabian." Saat tahapan kenabian berakhir dengan wafatnya Nabi Muhammad Saw, Sadra berbendapat bahwa tahapan berikutnya adalah imāmah/wișāyah yang terdiri dari 12 imam Syiah.

Persoalan Imamah (kepemimpinan religius dan politik) muncul sejak Nabi Saw. wafat pada 632 M. Bagi Syiah, Imamah menjadi salah satu pokok agama (ușūl al-dīn). Menurut Syiah Imamiyah, penentuan Imamah didasarkan pada dua prinsip: pertama, prinsip nas, yakni bahwa Imamah merupakan hak prerogatif yang diberikan Allah kepada tokoh terpilih dari keluarga Nabi Saw., yang sebelum kematiannya dengan bimbingan Allah menunjuk penggantinya melalui penunjukan yang jelas (naș). Kedua, adalah prinsip 'ilm. Yakni bahwa seorang Imam dianugerahi sejumlah khusus ilmu pengetahuan agama yang diperolehnya melalui ilham Ilahi dan tidak dimiliki oleh orang lain manapun, serta hanya bisa diturunkan sebelum kematiannya kepada Imam berikutnya. ${ }^{23}$

23 Abdulaziz Sachedina, "Imāmah" dalam John L. Esposito (Ed.), Ensiklopedi Oxford Dunia Islam Modern, terj. Eva YN dkk. (Bandung: Mizan, 2002) Jilid 2, h. 293-294. 
Meski demikian terdapat perbedaan antara beberapa kelompok Syiah terbesar: Ismā'̄iliyah, Imāmiyah, dan Zaidiyah. Zaidiyah tidak menganggap imāmah terbatas pada keturunan 'Alī melalui putranya, al-Husain, melainkan juga Imam lain dari Ahlul-bait yang melawan penguasa yang tidak sah. Bagi Imāmiyah, Imam memiliki otoritas politik, sedangkan bagi Zaidiyah imam tidak bergantung pada otoritas politik. Namun ketiga kelompok mengakui bahwa Imam dipandang sebagai penafsir "maksum" atas wahyu kenabian.

Dengan berbagai otoritas tersebut, para Imam juga berfungsi sebagai wasilah (perantara) antara manusia dan Tuhan. Meminta pertolongan kepada mereka dianggap telah memohon kepada Tuhan melalui saluran yang telah disediakan Tuhan di hadapan manusia. Berdasarkan doa tawassul yang hingga hari ini diamalkan oleh jamaah Ahlul-bait, dapat dipastikan bahwa mereka juga mengamalkan atau bahkan mengharuskan "tawassul bi al-dhāt", yakni bahwa tawassul dapat dilakukan melalui figur yang telah meninggal seperti Nabi Saw., Fatimah Ra, 'Alī bin Abī Ṭālib dan 11 Imam sesudahnya.

\section{MOTIVASI ZIARAH: PERSPEKTIF ANTROPOLOGIS}

Studi-studi tentang ziarah telah banyak dilakukan, banyak informasi yang dapat digali secara antropologis untuk mengetahui motivasi ziarah. Sementara tempat-tempat ziarah tertentu telah menghasilkan keuntungan ekonomis yang tidak sedikit bagi pemerintah dan menghidupkan perekonomian masyarakat sekitar. Bagi negara-negara Islam, wisata ziarah juga layak dikembangkan untuk meningkatkan pendapatan negara.

Untuk mengetahui motivasi-motivasi seseorang dalam berziarah, studi-studi antropologis tentang ziarah menarik untuk disimak. Di Indonesia, misalnya di Jawa, tradisi ziarah cukup kuat berakar dalam masyarakat. Melalui studi terhadap masyarakat peziarah di makam Sunan Tembayat di Desa Paseban, Bayat, Klaten, Makruf membantah segregasi sosial seperti pandangan Clifford Geertz. 
Makruf melihat bahwa motivasi dan cara seseorang melakukan ziarah bermacam-macam. Pertama, ia menemukan seseorang yang melaksanakan ziarah secara berkelompok, dan melakukan zikir tertentu dalam beberapa hari. Mereka menurutnya adalah "peziarah sufi" yang melakukan ziarah keliling Pulau Jawa terhadap setiap makam yang dianggap sebagai makam wali. Kedua, ialah kelompok lain yang melakukan ziarah sendiri-sendiri atau kelompok. Berbeda dengan kelompok tarekat, para peziarah ini melakukannya dengan membawa bunga dan/atau kemenyan dan wangi-wangian lainnya. Mereka menyebut ritualnya sebagai "nyekar", menabur bunga. Selain ziarah, biasanya mereka akan mendatangi juru kunci untuk mengutarakan niatnya agar terkabul. Ada yang minta lulus sekolah, ada yang minta usahanya sukses, ada yang minta tanahnya subur dan sebagainya. Selain itu, ada juga beberapa individu yang dengan santai melakukan ziarah dan umumnya warga sekitar Tembayat, mereka ini menganggap kedatangannya ke makam Sunan Tembayat sebagai "sowan." Mereka ini menganggap kunjungan ke makam Tembayat tak ubahnya mengunjungi orang tua sendiri, karena itu tak ada ritual atau permintaan khusus. ${ }^{24}$

Studi antropologis juga digambarkan oleh Richard ${ }^{25}$ terhadap komunitas peziarah di Iran. Berdasarkan studi-studi tersebut, Richard menyebut tiga motivasi melakukan ziarah. Motivasimotivasi tersebut ialah, pertama: memanfaatkan khalwat dan memetik hikmah agar dekat dengan Tuhan dan memperoleh kesempurnaan (kämil) ruhani dan "terjamin" berada di jalur kebenaran. Oleh karena itu, wali yang diziarahi ialah tokoh yang dianggap memiliki derajat "kāmil mukammil." Kedua, untuk menyampaikan permohonan-permohonan kepada Sang Khalik, permohonan-permohonan ini bisa jadi bersifat pribadi dan duniawi. Ketiga, karena "hubungan yang hangat" antara peziarah dan objek yang diziarahinya, hubungan ini -sebagaimana disebut

24 Jamhari Makruf, "In the Center of Meaning: Ziarah Tradition in Java" dalam Studia Islamika, Indonesian Journal for Islamic Studies, Vol. 7, No. 1, 2000, 67, 69; lihat juga, Jamhari Makruf, Dari Ziarah Makam Wali ke Terorisme, Pidato Ilmiah Pengukuhan Guru Besar Ilmu Antropologi Fakultas Ilmu Dakwah dan Ilmu Komunikasi, UIN Syarif Hidayatullah Jakarta, 2014, h. 10-11.

25 Yann Richard, "Iran”, dalam Henri Chambert-Loir dan Claude Guillot (ed.), Ziarah dan Wali di Dunia Islam, terj. Jean Couteau, dkk. (Jakarta: Serambi-EFEO-Forum Jakarta Paris), 2007, h. 221222, 226-227. 
Richard dengan mengutip Betteridge- bahkan lebih hangat daripada keluarga.

Dari dua studi tersebut, terlihat bahwa apa yang dilakukan oleh "peziarah sufi" seperti disebut oleh Makruf dilakukan oleh orang-orang yang haus akan bimbingan ruhani agar mencapai kesempurnaan spiritual. Sementara itu, memang ada sekelompok orang yang sudah memiliki kedekatan batin dengan objek yang diziarahi sehingga, hubungan ini bahkan lebih dekat daripada keluarga. Meskipun hubungan itu bisa jadi berawal dari hubungan keluarga atau hubungan guru-murid, namun hubungan tersebut telah meningkat menjadi hubungan "kasih sayang" dan "kesatuan batin". Sementara pada uraian di bawah, penulis melihat bahwa kedua studi membuktikan bahwa praktek ziarah lebih "luwes" daripada konsep-konsep teologis dari dua tradisi tersebut.

Saat menyampaikan maksud-maksud atau hajatnya, selain bahasa dan tatacara formal, Richard juga menjumpai pola-pola penyampaian hajat yang menurutnya jauh dari kesan formal, melainkan sangat manusiawi dan bahkan polos. Permohonanpermohonan yang disampaikan dengan sangat formal, misalnya terjadi pada peziarah di makam Imam Riḍá (w. 203 H/818 M). Ritus-ritus ziarah di sini, sebut Richard ${ }^{26}$, sangat ketat: pertamatama peziarah harus dalam keadaan suci, berpakaian baru atau bersih, bersikap serius dan resmi, menggunakan wangi-wangian (kecuali di makam Imam Husain bin 'Ali RA), dan mengucapkan puji-pujian kepada Nabi Saw dan keluarganya. Sesampainya di makam, peziarah berhenti di ambang pintu untuk berdoa, lebih sering sambil membungkuk, menciumi ambang pintu atau pintu, dan mengucapkan kalimat untuk memohon izin masuk ke dalam.

Sebelum menyampaikan permohonan yang bersifat pribadi dan khusus, peziarah harus melakukan berbagai ritus wajib, misalnya membaca teks untuk setiap wali yang bersangkutan (ziyārat nāma), jalan mengelilingi makam, menciumi makam atau pagar keliling, serta doa wajib yang diucapkan di kepala (bālāsari) makam. Hal itu terjadi pada ritual khusus di makam-makam para Imam.

26 . Yann Richard, “Iran”, h. 227-228. 
Sementara di makam-makam lain atau dalam situasi umum, permohonan-permohonan tersebut selain ada yang disampaikan dengan hidmat dan penuh keberserahan, juga ada yang disampaikan dengan "keangkuhan" dan penuh perhitungan. Selain sumpah atas nama Allah, Para Rasul, semua wali dan malaikat, kadang juga pemohon mengancam akan melakukan protes langsung kepada (perantara) Nabi Muhammad Saw., Zahra (nama lain dari Fatimah Ra), Imam Husain jika doanya tak terkabul. Atau bahkan jika tidak terkabul juga, mengancam akan mengadu kepada Abūl Faḍl ('Abbās), yang dikenal sebagai pelindung kaum miskin. Bahkan ada juga yang disampaikan dengan ultimatum, apabila permohonannya tidak dipertimbangkan ia akan meninggalkan agama, meninggalkan al-Quran atau apabila meninggal dalam keadaan kafir; dan "perantara"-lah yang patut dikecam. Sebaliknya jika permohonan telah terkabul mereka akan membayar nazri (nazar) yang sebagian besar berupa makanan.

Berbagai macam "pendekatan" terhadap wasilah tersebut bukannya tanpa kritik dari ulama Syiah. Muthahhari misalnya menyebutkan bahwa terdapat wasilah yang dilarang, yakni "menekan/membujuk" dengan berbagai cara (uang, pengaruh, kekuasaan) untuk mendapatkan apa yang sesungguhnya kita tidak berhak dari sudut agama. Karena hal tersebut berarti beranggapan bahwa di hadapan kekuasaan mutlak Allah ada perampas-perampas potensial yang menentang Keesaan-Nya. Atau dengan kata lain beranggapan bahwa kita dapat mendekati Allah dengan menyenangkan Imam ini atau itu dengan cara yang lain dari menyenangkan Allah. Sebaliknya, wasilah yang halal dan baik adalah berupa bimbingan, perbuatan, serta pengampunan. Yakni bahwa Para Imam memiliki perbuatan yang patut menjadi panutan untuk pengikutnya dan Para Imam membawa "panji kebaikan" yang berkahnya akan sampai ke pengikutnya. Sedangkan wasilah pengampunan mengandaikan adanya kasih sayang tak terbatas dari Allah melalui penyelamatan (penyucian) bagi mereka yang siap menerimanya (melakukannya). 


\section{E. SERANGAN MEMATIKAN TERHADAP PEZIARAH DI PERBATASAN PAKISTAN-IRAN}

Komunitas Syiah di Pakistan merupakan kelompok Syiah terbesar kedua di dunia setelah Iran. Dua puluh persen dari 180 juta penduduk Pakistan adalah Muslim Syiah. ${ }^{27}$ Mereka terkonsentrasi di beberapa kota yakni: Karachi, Lahore, Multan, Rawalpindi, Islamabad, Jhang, Peshawar, Parachinar, Kohat, dan Quetta. Muslim Sunni dan Syiah telah hidup damai selama tiga dasawarsa (1947-1977) sejak berdirinya Negara Pakistan pada 15 Agustus 1947. Salah seorang pendiri Pakistan juga berasal dari komunitas Syiah, yakni Muhammad Ali Jinnah (1876-1948 M).

Namun pada akhir dasawarsa 1970-an hubungan Sunni-Syiah memanas. Ada tiga faktor yang menurut Majidyar ${ }^{28}$ menyebabkan situasi tersebut, yakni: naiknya Jenderal Muhammad Zia-ul-Haq dalam kekuasaan, Revolusi Islam Iran, dan perang syaraf Pakistan di Afghanistan dan Kashmir. Setelah Zia-ul-Haq memakzulkan pemerintahan Bhutto di musim panas 1977, ia melakukan berbagai program Islamisasi yang merugikan bagi harmoni Sunni-Syiah hingga hari ini. Program Islamisasi -yang oleh Syiah dianggap sebagai "Sunnifikasi"- tersebut misalnya pemungutan zakat dan perberlakuan hukum syariat Islam seperti hukuman mati dengan cara dirajam dan dilempari batu.

Sementara kelompok Syiah yang belakangan terinspirasi oleh Revolusi Iran pada tahun1978-1979, melakukan protes terhadap pemerintah Zia-ul-Haq atas pungutan zakat yang dilakukan oleh pemerintah karena selama ini mereka telah membayar zakat melalui ulama Marja’iyya mereka. Bertepatan dengan bulan-bulan terjadinya Revolusi Islam, komunitas Syiah berkumpul di Punjab melakukan protes pemungutan zakat dan menuntut agar fikih Jafari (Syiah) diakui dalam sistem hukum di Pakistan dan disatukan dalam Tehrike-e Nifaz-e Fiqh-e Jafari (TNFJ). Hal ini pun menambah

27 Ahmad Khalid Majidyar, "The Shi'ites of Pakistan: A Minority under Siege", dalam American Enterprise Institute for Public Policy Research, June 2014, h. 1; Shehryar Fazli, "Sectarianism and Conflict: The View from Pakistan”, 1 dalam Manni Crone dan Mona Kanwal Sheikh (ed.), Religion and Violence. Dokumen diunduh dari https://www.diis.dk..

28 . Majidyar, “The Shi'ites of Pakistan”, h. 2. 
geram elit-elit Sunni di Pakistan. Hal tersebut kelak menyebabkan kontak-kontak fisik antar kedua kelompok tidak terhindarkan.

Suksesi revolusi Islam di Iran juga menyebabkan tumbuhnya kelompok Syiah revolusioner di Iran. Bahkan seolah Iran memang hendak mengekpor revolusi tersebut dengan memberikan beasiswa terhadap 4000 pelajar Syiah Pakistan untuk belajar "Wilāyah alFaqīh" di Iran. Mereka yang terpengaruh pemikiran Khomeini kemudian membentuk The Imamia Students Organisation (ISO). Tumbuhnya Syiah revolusioner tentu menimbulkan kecemasan bagi Amerika Serikat (AS), elit Sunni di Pakistan dan monarki lain di Teluk Persia. Oleh karena itu, Saudi Arabia kemudian turut campur tangan terhadap elit Sunni di Pakistan. Saudi Arabia menyokong terbentuknya kelompok Sunni garis keras Sipah-e Sahaba Pakistan (SSP) pada 1985. Sementara kelompok Syiah membelot dari ISO dan membentuk Sipah-e Muhammad Pakistan (SMP).

Keterlibatan Islamabad dalam mendukung kelompokkelompok militan di perbatasan Kashmir dan Afghanistan selama 1980-1990 juga turut memperdalam deviasi Sunni-Syiah. Melalui bantuan dana yang massif dari AS, dan Saudi Arabia ${ }^{29}$, Zia-ul-Haq membangun kamp-kamp di perbatasan Pakistan untuk Mujahidin Afghan yang anti-Soviet dan kelompok teroris anti-India. Penceremah-penceramah radikal dan militan seperti pemimpin alQaeda, Osama bin Laden memperoleh suaka di Pakistan. Madrasahmadrasah pun menjadi tempat pembibitan kelompok radikal dan teroris.

Akibatnya pasca penarikan Uni Soviet dari Afghanistan pada 1989, beberapa kelompok militan memusatkan perhatiannya pada kelompok Syiah. Perang Amerika terhadap kelompok teroris pasca serangan WTC 11/9/01 hanya menunda perhatian kelompok radikal terhadap Syiah. Atas tekanan Amerika Musharraf melarang

29 Majidyar, "The Shi'ites of Pakistan", 6; Fazli, "Sectarianism and Conflict: The View from Pakistan", 1; ada juga laporan tentang sumbangan pribadi dari Arab untuk LeJ dalam membuat gerakan anti Syiah, lihat: Human Rights Watch, "We Are The Walking Dead: Killings of Shia Hazaras in Balochistan, Pakistan", Juni 2014, h. 12; dokumen diunduh dari https://www.hrw.org; Tony Cartalucci, "Destroying a Nation State: US-Saudi Funded Terrorists Sowing Chaos in Pakistan," Center for Research on Globalization, February, 2013, http://www.globalresearch.ca/destroyinga-nation-state-us-saudi-funded-terrorists-sowingchaos-in-pakistan/5323295, diakses 20 Oktober 2018). 
organisasi kelompok-kelompok radikal semacam SSP, SMP, Jaishe-Mohammad, and Lashkar-e-Jhangvi (LeJ). ${ }^{30}$ Untuk meredakan tekanan tersebut Musharraf memang melarang organisasiorganisasi tersebut, namun kelompok-kelompok tersebut tetap beroperasi dalam federasi kesukuan.

Eskalasi konflik antara Sunni ekstrim dengan Syiah di Pakistan mulai memanas sejak tahun 1980-an. Namun serangan-serangan yang mematikan meningkat sejak tahun 2008, tepatnya sejak pemecatan Musharraf ${ }^{31}$. Serangan tersebut terutama terjadi di empat wilayah yakni: Kurram Agency, Quetta, Karachi, dan Gilgit Baltistan. Pada tahun 2013 laporan Pakistan Institute for Peace Studies menyebut bahwa serangan sektarian di Pakistan meningkat 53 persen, 85 persen diantaranya terjadi di empat daerah di atas. ${ }^{32}$

Majidyar memperkirakan bahwa dalam beberapa tahun terakhir sampai artikelnya ditulis (Juni 2014) korban serangan mematikan di Kurram Agency saja mencapai 2000 pengikut Syiah. Sementara harian Kompas (09/06/2014) menyebut bahwa dalam dua tahun terakhir (2012-2013) hampir 1000 umat Syiah tewas dalam berbagai aksi kekerasan. Jumlah tersebut cukup besar mengingat bahwa pengikut Syiah hanya 20 persen dari 180-an juta Muslim Sunni di Pakistan.

Sementara laporan Bueno de Mesquita ${ }^{33}$ menyebutkan bahwa sepanjang 1988-2011 serangan teroris di Pakistan telah merenggut nyawa 5.783 orang. Sedangkan korban kekerasan politik dan lainnya mencapai 35.839 orang. Sedangkan korban perang Pakistan (1947, 1965, 1971, 1999) hanya mencapai lebih dari 9.000 jiwa. Artinya

30 LeJ merupakan kelompok ekstremis militan Sunni Deobandi, dibentuk tahun 1996 sebagai salah satu faksi dari kelompok militan Sipah-e-Sahaba Pakistan (SSP). Kelompok LeJ memandang Muslim Syiah sebagai kelompok sesat (heretik) dimana pembunuhan terhadap mereka dianggap dibenarkan menurut agama.

31 . Musharraf lahir 11 Agustus 1943 dan memerintah pakistan sejak 12 Oktober 1999 dengan mengangkat dirinya sebagai Ketua Eksekutif melalui kudeta; kemudian pada 20 Juni 2001 mengangkat dirinya sebagai Presiden, namun pengadilan memerintahkan untuk menyelenggarakan pemilu pada 12 Oktober 2002, dan ia kemudian duduk menjadi presiden. Musharraf sempat menjabat presiden untuk kedua kalinya sebelum mengundurkan diri pada 8 Agustus 2008.

32 . Majidyar, "The Shi'ites of Pakistan: A Minority under Siege”, h. 1.

33 . Dalam C. Christine Fair, "Explaining Support for Sectarian Terrorism in Pakistan: Piety, Maslak, dan Sharia," dalam www.mdpi.com/journal/religions 25 September 2015, Religions 2015, 6, 1137-1167; doi:10.3390/rel6041137, 1140. 
bahwa korban serangan teroris dan kekerasan komunal lainnya jauh melebihi korban perang Pakistan.

Beberapa serangan-serangan tersebut sebagian menyasar para peziarah; khususnya Syiah. Berikut ini penulis mencatat beberapa serangan teroris terhadap para peziarah dengan korban yang cukup banyak. Tentu lebih banyak lagi serangan-serangan tersebut yang tidak hanya menyasar para peziarah, atau serangan terhadap ziarah yang korbannya relatif sedikit, misalnya 1-5 orang. Fazli melaporkan serangan teror yang dilakukan oleh LeJ terhaadap peziarah di distrik Mastung Baluchistan pada 29 september 2010 yang menewaskan 29 peziarah Syiah. ${ }^{34}$

Serangan teroris cukup besar yang menimpa peziarah juga terjadi pada 30 Desember 2012. Saat itu, serangan bom menimpa para peziarah yang hendak menuju Iran. Serangan ini menewaskan 17 peziarah di distrik Mastung, Baluchistan. Harian Kompas juga melaporkan bahwa sebulan sebelumnya (Nopember 2012) serangan serupa telah mengakibatkan 23 orang Muslim Syiah terbunuh di Rawalpindi. ${ }^{35}$

Berikutnya, Januari 2014, serangan bom mobil (21/1/2014) menimpa peziarah yang hendak pulang dari Iran dan melintasi jalan raya Iran-Pakistan sekitar $60 \mathrm{KM}$ dari Quetta. Serangan tersebut menewaskan 22 peziarah, dari 51 penumpang. ${ }^{36}$ Serangan hebat berikutnya terjadi pada 8/6/2014 saat sebuah bus yang membawa peziarah Syiah dari Pakistan kembali dari kunjungan mereka di situs suci Syiah di Iran. Bus itu berhenti di sebuah rumah makan di kota Taftan, Provinsi Baluchistan, 700 kilometer dari kota Quetta. Saat itulah empat pelaku bom bunuh diri menyerang rumah makan itu. "Secara total 24 peziarah Syiah meninggal termasuk 10 perempuan, dan 13 orang lainya terluka." ${ }^{37}$

34 . Fazli, "Sectarianism and Conflict: The View from Pakistan", h. 2.

35 Lihat, Kompas.com, “Bus Peziarah Syiah Dibom, 17 Tewas”, https:// tekno.kompas.com/ $\mathrm{read} / 2012 / 12 / 30 / 16000277 / B u s . P e z i a r a h . S y i a h . D i b o m . .17 . T e w a s$, diakses 29 Oktober 2018.

36 Lihat, Kompas.com, “Bus Peziarah Syiah Pakistan Dihantam Bom, 22 Tewas”, dalam https:// internasional.kompas.com/read/2014/01/21/2235050/Bus.Peziarah.Syiah.Pakistan.Dihantam. Bom.22.Tewas, diakses 29 Oktober 2018.

37 Majidyar, "The Shi'ites of Pakistan: A Minority under Siege", 1; Lihat, Kompas.com: "Peziarah Syiah Pakistan Diserang Bom Bunuh Diri, 24 Tewas", https://internasional. kompas.com/

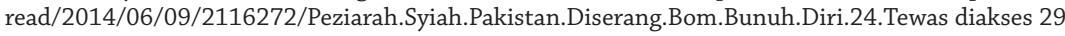


Merujuk pada jumlah korban-korban di atas rekonsiliasi harus segera dilakukan, namun penyerangan-penyerangan terhadap peziarah di Pakistan nampaknya tidak sepenuhnya berasal dari perbedaan teologis melainkan berkelindan dengan persaingan politik dan kekuasaan; baik antar elit di Pakistan, maupun persaingan negara-negara di kawasan tersebut. Dalam peta politik global, dalam kelompok Syiah terdapat permainan Iran yang ingin melindungi dirinya dari musuh utama AS. Sebaliknya di elit Sunni ada Arab Saudi dan monarki lainnya yang terancam dengan visi revolusi Iran. Oleh karena itu, Majidyar menawarkan tiga solusi untuk meminimalisir konflik-konflik sektarian di Pakistan, yakni: pertama, reformasi sistem pendidikan yang menutup ruang-ruang militansi di madrasah. Kedua, membatasi dana-dana asing untuk kelompok-kelompok ekstremis. Ketiga, menerapkan program deradikalisasi dengan mempromosikan interfaith harmony. ${ }^{38}$

Salah satu permasalahan serius disebut oleh Majidyar ialah bagaimana pemerintah melawan ungkapan kebencian dari kelompoksektarian yang menganggap Syiah sebagaikafir. Anggapan tersebut nampaknya bukan isapan jempol belaka, mengingat bahwa Survei Pew Research Center pada 2012 menyebutkan bahwa $41 \%$ Muslim Sunni menganggap Syiah sebagai komunitas di luar Islam. ${ }^{39}$ Sementara laporan Human Rights Watch ${ }^{40}$ menjumpai selebaran-selebaran di wilayah Quetta yang menyebutkan bahwa Syiah sebagai kafir. Selebaran dan ancaman pembunuhan tersebut dikeluarkan oleh pimpinan LeJ.

\section{F. KESIMPULAN}

Berdasarkan uraian-uraian di atas dapat disimpulkan bahwa: pertama, secara konseptual terdapat perbedaan pemahaman terhadap wasīlah (tawassul) antara Sunni Ortodoks, Salafi-Wahabi, dan Syiah Imamiyah. Baik Sunni Ortodoks dan Syiah Imamiyah

Oktober 2018.

38 Majidyar, "The Shi'ites of Pakistan: A Minority under Siege”, h. 5-6.

39 Pew Research Center, "The World's Muslims: Unity and Diversity," August 9, 2012, www. pewforum.org/2012/08/09/theworlds-muslims-unity-and-diversity-executive-summary/.

40 Human Rights Watch, “We Are The Walking Dead”, h. 11, 14, 58-59. 
memahami tawassul bisa diperoleh secara dhātiyah, artinya meskipun seseorang telah meninggal wasilah dapat diperoleh. Hal ini terjadi dengan satu prinsip bahwa berkah dari wasillah tersebut terjadi atas izin dan anugerah Allah. Sedangkan kelompok SalafiWahabi berpendapat bahwa wasillah hanya diperbolehkan terhadap subjek yang masih hidup. Perbedaan pendapat ini menentukan boleh atau tidaknya kegiatan ziarah di negara-negara yang menganut ideologi Salafi-Wahabi seperti Saudi Arabia. Namun hal yang jauh lebih penting adalah konsep al-wala' wa al-bara' dan sikap Salafi-Wahabi terhadap Syiah sebagai bidah.

Kedua, dalam tataran praksis antropologis, kegiatan ziarah ternyata lebih "luwes" daripada konsep-konsep teologis yang membatasinya. Dalam praktik ziarah di Iran, peziarah "memperlakukan" figur yang diziarahi sebagai subjek hidup yang menerima keluhan, bisa dibujuk atau bahkan diancam. Sementara dalam praktik ziarah di Indonesia pola-pola permintaan tidak disertai "ancaman" melainkan disampaikan secara halus melalui juru kunci makam.

Ketiga, dalam konteks peziarah sebagai korban konflik mematikan di Pakistan. Konflik antara Sunni-Syiah di Pakistan sangat komplek karena melibatkan berbagai kepentingan. Konflik ini memanas sejak Muhammad Zia-ul-Haq memegang kekuasan pada tahun 1977. Konflik serupa juga nyaris selalu terjadi setiap pergantian kepemimpinan seperti saat Pervez Musharraf mengambil alih kekuasaan pada 1999-2008. Konflik Sunni-Syiah di Pakistan juga diperparah oleh campur tangan negara-negara lain seperti Amerika Serikat, Saudi Arabia dan Iran. Sehingga untuk meredam konflik tersebut pemerintah Pakistan harus memastikan pemerintahan sesuai konstitusi, dan membatasi campur tangan negara lain. Salah satu hal yang harus menjadi perhatian adalah upaya inter faith dialog agar terjadi saling memahami antara kelompok Sunni dan Syiah. Upaya tersebut juga akan sulit terlaksana tanpa melakukan reformasi kurikulum madrasah untuk membatasi ide-ide militan. 


\section{DAFTAR PUSTAKA}

Al-Bukhārī, Abū 'Abdillāh Muhammad Ibn Ismā'îl. Șahīh al-Bukhārī, Taḥqīq: Muhammad Zuhayr bin Nāṣir al-Nāșir. t.k.: Dār Ṭūq al-Najāh, 1422 H.

Al-Hakīm, Su'ād. Al-Mu'jam al-Ṣūfí: al-Hikmah fì hudūd al-kalimah. Beirut: Dandāh Lițtabā'ah wa al-Nashr, 1981.

Al-Munāwī, Zayn al-Dīn Muhammad 'Abd al-Ra'ūf bin Tāj al-Ārifīn al-Haddādī, Fayḍ al-Qadìr Sharh al-Jāmi' al-Ṣaghìr. Mesir: Maktabah al-Tijāriyah al-Kubrá, 1356 H (1937/38 M).

Al-Naysābūrī, Abū 'Abdullāh Muhammad bin 'Abdullāh al-Hākim. Al-Mustadrak 'alá al-Saḥịhayn li al-Ḥākim, Taḥiīq: Abū 'Abd al-Raḥmān Muqbil. Al-Qāhirah: Dār al-Haramayn, 1997.

Al-Naysābūrī, Abū al-Ḥasan Muslim bin al-Ḥajjāj al-Qushayrī. AlMusnad al-Ṣahịh al-Mukhtașar bi Naql al-'Adl 'an al-'Adl ilá Rasūlillāh Sallállāhu 'alayhi wa sallam, Tahqīq: Muhammad Fu’ād 'Abd al-Bāqī. Beirut: Dār Ihyyā’ al-Turāth al-'Arabī, t.t. .

Al-Sijistānī, Abū Dāwud Sulaymān bin al-Ash'ath bin Isḥāq al-Azdī. Sunan Abī Dāwud, Tahqiī: Shu'ayb al-Arna'ūț, Muhammad Kāmil Qarah Balilī. Beirut: Dār al-Risālah al-Ālamiyyah, 2009.

Al-Tirmidhī, Abū 'Abdullāh Muḥamad bin 'Alī bin Ḥasan al-Ḥakīm. Kitāb Khatm al-Awliyā', Taḥīq: 'Uthmān Ismā'īl Yaḥyā'. Beirut: Al-Mațbaah al-Kāthawlikiyah, t.t..

Anwar, Rosihon. "Tafsir Esoterik Al-Qur'an Menurut AlThabāthabā'î." Jakarta: Disertasi Program Pascasarjana UIN Syarif Hidayatullah Jakarta, 2003.

Asshodiq, M. Ja'far. “Studi Komparasi Tentang Pemahaman HadisHadis Tawasssul, Munurut Nahdlatul Ulama dan Wahabi”. Surabaya: Tesis Progrm Studi Imu Hadis Pascasarjana UIN Sunan Ampel, 2018.

Baalbaki, Munir dan Rohi Baalbaki. Kamus al-Maurid, terj. Achmad Sunarto. Surabaya: Halim Jaya, 2006. 
Budiman, Ikhlas (Peny.). Doa Tawassul Doa Kumail Doa Jausyan Kabir. Jakarta: Al-Huda, 2004.

Ebadi, Mehdi. "Shrine Pilgrimage (Ziyārat) in Turco-Iranian Cultural Regions" dalam International Journal of Religious Tourism and Pilgrimage, Vol. 4: Iss. I, Article 7, 69-77.

Fair, C. Christine, "Explaining Support for Sectarian Terrorism in Pakistan: Piety, Maslak, dan Sharia," dalam www.mdpi. com/journal/religions 25 September 2015, Religions 2015, 6, 1137-1167; doi:10.3390/rel6041137.

Fakhry, Majid. Sejarah Filsafat Islam: Sebuah Peta Kronologis, terj. Zaimul Am. Bandung: Mizan, 2002.

Farih, Amin. "Paradigma Pemikiran Tawassul dan Tabarruk Sayyid Ahmad Ibn Zaini Dahlan di Tengah Mayoritas Teologi Mazhab Wahabi," dalam Jurnal Theologia. Vol. 27, Nomor 2, Desember 2016, 279-304.

Fazli, Shehryar. "Sectarianism and Conflict: The View from Pakistan" 1-4; dalam Manni Crone dan Mona Kanwal Sheikh (ed.), Religion and Violence. Diunduh dari https://www.diis.dk..

Huda, Sokhi. "Global Salafism Perspektif Baru tentang Keunikan Radikalisme Islam” dalam Kontemplasi, Vol. 8, No. 2, Nopember 2011, 213-229.

Majidyar, Ahmad Khalid. "The Shi'ites of Pakistan: A Minority under Siege", dalam American Enterprise Institute for Public Policy Research, June 2014. Diunduh dari www.aei.org.

Makruf, Jamhari. "In the Center of Meaning: Ziarah Tradition in Java" dalam Studia Islamika, Indonesian Journal for Islamic Studies, Vol. 7, No. 1, 2000, 51-90.

Makruf, Jamhari. Dari Ziarah Makam Wali ke Terorisme, Pidato Ilmiah Pengukuhan Guru Besar Ilmu Antropologi Fakultas Ilmu Dakwah dan Ilmu Komunikasi, UIN Syarif Hidayatullah Jakarta, 2014.

Martin, Richard C. (ed.). Encyclopedia of Islam and The Muslim World (USA: Macmillan Reference USA-Thomson Gale, 2003.

Richard, Yann, "Iran", dalam Chambert-Loir, Henri dan Claude 
Guillot (ed.), Ziarah dan Wali di Dunia Islam, terj. Jean Couteau, dkk. (Jakarta: Serambi-EFEO-Forum Jakarta Paris), 2007, 217-233.

Sachedina, Abdulaziz. "Imāmah" dalam John L. Esposito (Ed.), Ensiklopedi Oxford Dunia Islam Modern, terj. Eva YN dkk. (Bandung: Mizan, 2002) Jilid 2.

Wehr, Hans. A Dictionary of Modern Written Arabic. Beirut-London: Librairie du Liban-Macdonald \& Evans LTD, 1974.

\section{Internet:}

Cartalucci, Tony. "Destroying a Nation State: US-Saudi Funded Terrorists Sowing Chaos in Pakistan," Center for Research on Globalization, February, 2013, http://www.globalresearch. ca/destroying-a-nation-state-us-saudi-funded-terroristssowingchaos-in-pakistan/5323295, diakses 20 Oktober 2018).

Human Rights Watch, "We Are The Walking Dead: Killings of Shia Hazaras in Balochistan, Pakistan", Juni 2014, dokumen diunduh dari https://www.hrw.org.

Kompas.com, "Bus Peziarah Syiah Pakistan Dihantam Bom, 22 Tewas", dalam https://internasional.kompas.com/ read/2014/01/21/2235050/Bus.Peziarah.Syiah.Pakistan. Dihantam.Bom.22.Tewas, diakses 29 Oktober 2018.

Kompas.com, "Peziarah Syiah Pakistan Diserang Bom Bunuh Diri, 24 Tewas”, https://internasional.kompas.com/ $\mathrm{read} / 2014 / 06 / 09 / 2116272 /$ Peziarah.Syiah.Pakistan. Diserang.Bom.Bunuh.Diri.24.Tewas diakses 29 Oktober 2018.

Pew Research Center, "The World's Muslims: Unity and Diversity," August 9, 2012, www.pewforum.org/2012/08/09/ theworlds-muslims-unity-and-diversity-executivesummary/. 